ESPECIAL

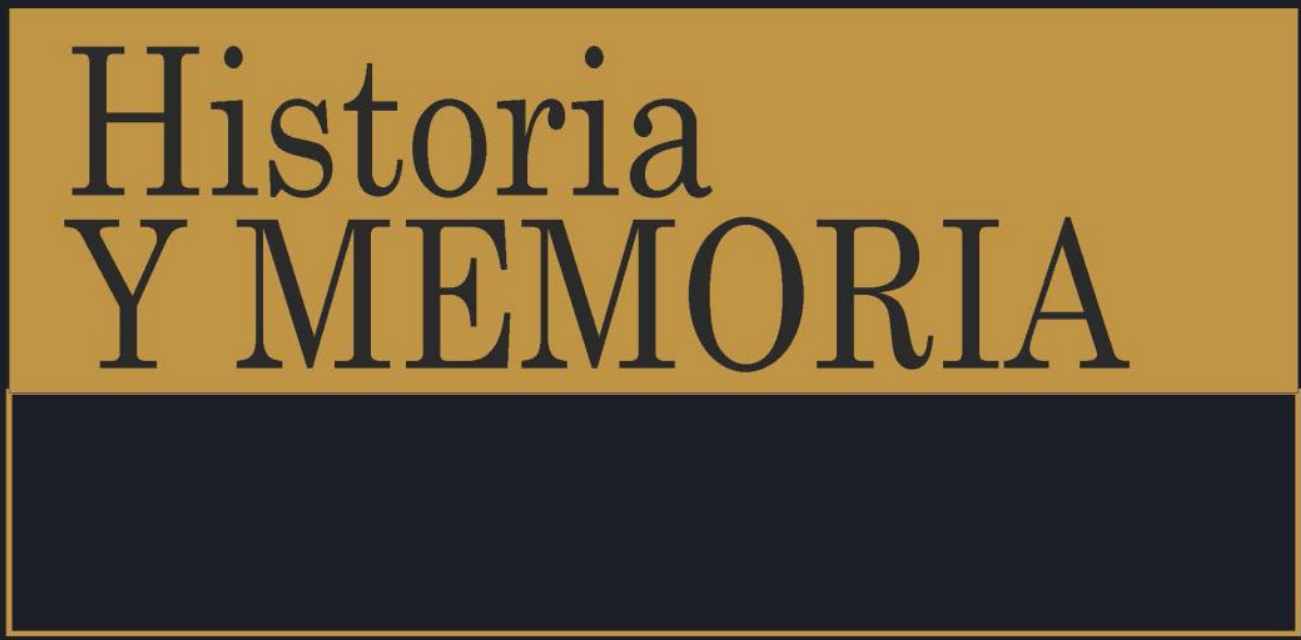

ISSN: 2027-5137 Número Especial • 10 Años • Año 2020 - Tunja, Colombia

\title{
Historia de las emociones: ¿qué se cuentan los afectos del pasado?
}

https://doi.org/10.19053/20275137.nespecial.2020.11583

Begoña Barrera María Sierra

Páginas 103-142

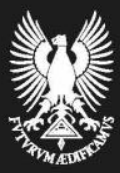




\title{
Historia de las emociones: ¿qué cuentan los afectos del pasado?*
}

\author{
Begoña Barrera ${ }^{1}$ \\ María Sierra ${ }^{2}$ \\ Universidad de Sevilla- España
}

Recepción: 18/11/2019

Evaluación: 01/03/2020

Aprobación: 11/05/2020

Artículo de Investigación e Innovación

https:/doi.org/10.19053/20275137.nespecial.2020.11583

\section{Resumen}

Este artículo presenta una reflexión crítica sobre la historiografía dedicada al estudio de las emociones, mostrando su origen, sus logros y sus posibilidades. Para ello, el texto se organiza en tres recorridos que exploran 1) los paradigmas explicativos de lo emocional que más han influido en los planteamientos historiográficos; 2) el interés que los afectos

\footnotetext{
* Artículo realizado en el marco de los proyectos de investigación «Beyond stereotypes: Cultural Exchanges and the Romani Contribution to European Public Spaces (BESTROM)», financiado por Humanities in the European Research Area (HERA), e "Historia de los Gitanos: Exclusión, Estereotipos y Ciudadanía (Siglos XVIII-XX)» (HAR2015-64744-P), financiado por el Ministerio de Ciencia e Innovación de España (MICINN).

1 Investigadora posdoctoral, Universidad de Sevilla (España). Últimas 3 publicaciones: La Sección Femenina 1934 -1944. Historia de una tutela emocional (Madrid: Alianza Editorial, 2019); «Emociones para una identidad compartida. La Sección Femenina de FET-JONS entre la guerra y los años grises,» Historia y Política Vol. 42, (2019): 241-268; «La Sección Femenina en perspectiva. Historias y otros relatos sobre las mujeres de Falange,» Historia Contemporánea Vol. 62, (2020): 265 295. $\otimes$ b.barrera.lopez@hotmail.com (ㄱ https://orcid.org/0000-0001-5574-8479.

2 Profesora Catedrática de la Universidad de Sevilla (España). Últimas 3 publicaciones: «Creating Romanestan: A Place to be a Gypsy in Post-Nazi Europe,» European History Quarterly Vol. 49, $\mathrm{n}^{\circ} 2$ (2019): 272-292; «Hombres arcaicos en tiempos modernos: La construcción romántica de la masculinidad gitana,» Historia Social Vol. 93 (2019): 51-65; «Helios Gómez: la invisibilidad de la revolución gitana,» Historia y Politica Vol. 40, (2018): 83-114. $\bowtie$ msierra@us.es (1) https://orcid.org/00000002-6535-5078.
} 
han suscitado en la historiografía contemporaneísta desde principios del siglo XX hasta la llegada del llamado "giro afectivo»; y 3) la pluralidad de enfoques teóricos y categorías de análisis que los historiadores de las emociones han ido ofreciendo en las últimas décadas. Teniendo todo ello en cuenta, este artículo defiende lo oportuno de poner a dialogar la historia de las emociones con diferentes categorías de análisis, como el género o la raza, y lo ventajoso de abordar estos estudios desde otros enfoques, como la historia biográfica.

Palabras clave: Emociones, sentimientos, giro afectivo, género, raza, historia biográfica.

\title{
The history of emotions: what the affect of the past tells us
}

\begin{abstract}
This article presents a critical reflection on the historiography dedicated to the study of emotions, showing its origin, achievements and possibilities. For this, the text is organized in three sections which explore: 1 ) the explanatory paradigms of emotions which have influenced historiographic approaches; 2) the interest that affect has provoked in contemporary historiography from the early 20th century to the arrival of the so-called "affective turn»; and 3) the plurality of theoretical approaches and categories of analysis which historians of emotions have been offering in the last few decades. Taking the above into consideration, this article defends how appropriate it is to create a dialog between the history of emotions and different categories of analysis, such as gender or race, and how beneficial it is to address these studies from different approaches, such as biographical history.
\end{abstract}

Key Words: Emotions, feelings, affective turn, gender, race, biographical history. 


\section{L'histoire des émotions : ce que racontent les affects sur le passé}

\section{Résumé}

Cet article présente une réflexion critique sur l'historiographie dédiée à l'étude des émotions, tout en retraçant ses origines, ses acquis et ses possibilités. Pour ce faire, le texte analyse 1) les paradigmes explicatifs de l'émotionnel qui ont été décisifs pour l'historiographie; 2) l'intérêt que les affects ont suscité dans l'historiographie sur le contemporain depuis le début du $\mathrm{XX}^{\mathrm{e}}$ siècle jusqu'à l'arrivée de ce qu'on appelle "le tournant affectif»; 3) la diversité d'approches théoriques et des catégories d'analyse que les historiens des émotions ont conçu récemment. Dès lors, cet article se propose de montrer à quel point s'avère important le dialogue entre l'histoire des émotions et d'autres catégories d'analyse tels que le genre ou la race. Or, il convient aussi d'explorer d'autres perspectives, tels que l'histoire biographique.

Mots-clés: émotions, sentiments, tournant affectif, genre, race, histoire biographique.

\section{Introducción}

Seguramente no sea el más ingenioso de los dichos posibles, pero aquello de que la historia de las emociones levanta pasiones es una fórmula tan sencilla como oportuna para describir una circunstancia no muy común en los saberes científicos y humanísticos: que un campo de investigación suscite lo mismo que trata de comprender. En los últimos años, una perseverante curiosidad por saber qué son y de dónde vienen eso que llamamos afectos, pasiones, sentimientos o emociones, que ha atravesado la historiografía y ha alcanzado también a viejas conocidas suyas, como la antropología o la sociología, además de afectar a otras disciplinas, como la neurociencia, que ya se han convertido en asiduas a estos debates ${ }^{3}$. Y aunque

3 A lo largo del artículo se citarán algunos trabajos que diferencian entre estos términos, particularmente entre afecto y emoción como las dimensiones inconsciente y consciente del mismo fenómeno. Siguiendo una tendencia ya asentada en la 
en este frenesí multidisciplinar no todo ha sido armonía y consenso, las polémicas entre unas y otras han acabado por mostrar que la historiografía es hoy una de las disciplinas que más puede aportar a estas inquietudes colectivas.

Con la intención de justificar esto último, el presente artículo trata de reflexionar sobre la historiografía dedicada al estudio de las emociones mostrando su origen, sus logros y sus posibilidades. Para ello, el texto se organiza en tres recorridos que nos permitirán asomarnos a: 1) los paradigmas explicativos de lo emocional que, elaborados desde disciplinas adyacentes como las antes citadas, más han influido en los planteamientos historiográficos; 2) el despertar del interés por los afectos en la historiografía contemporaneísta a principios del siglo XX $\mathrm{y}$ sus aventuras y desventuras, al amparo de todos los giros del siglo hasta la llegada de su propio giro, el afectivo; y 3) la constelación de enfoques teóricos y categorías de análisis que los historiadores de las emociones han ido ofreciendo en las últimas décadas y que constituyen una caja de herramientas indispensable, no solo para una investigación centrada en la historia de las emociones, sino para cualquier exploración del pasado que se realice desde una mirada comprometida con el desmontaje de relatos esencializadores.

Confiamos en que este triple camino dibuje un panorama lo suficientemente amplio como para dar cuenta de las potencialidades de la historia de las emociones; unas potencialidades que, como expondremos en un último punto a modo de cierre, consideramos que todavía pueden multiplicarse aún más si las emociones son puestas en diálogo con diferentes categorías de análisis (como el género o la raza) y son trabajadas desde otros enfoques (como la historia biográfica). De este modo, trataremos de mostrar que la historia de emociones no es solo un campo de estudio con un objeto definido, sino que es -y lo es sobre todo- un terreno fértil desde el que seguir repensando cuestiones fundamentales, que afectan al debate general sobre la comprensión del pasado.

historiografía, y a sabiendas de que tal distinción puede entorpecer más que clarificar la explicación histórica, nosotras las emplearemos como sinónimos. 


\section{Ese oscuro objeto de investigación}

Las emociones nunca han sido materia ajena al pensamiento y a la erudición en Occidente. Desde la Antigüedad hasta la segunda mitad del siglo XIX, disciplinas como la filosofía y la teología, apoyadas en la retórica, la medicina y la literatura, fueron transformando paulatinamente la reflexión sobre los afectos. Con el inicio de la contemporaneidad, y sobre todo desde mediados del siglo XIX, este lugar quedó paulatinamente ocupado por la psicología experimental, cuyo predominio sería desplazado a finales del siglo pasado por la neurociencia ${ }^{4}$. La amplitud de interpretaciones, obras y autores que componen esta longeva tradición invita a considerar, antes que la relación histórica de contribuciones a la reflexión sobre las emociones, los paradigmas explicativos en los que estas aportaciones se han fundamentado.

En el desarrollo de tales modelos explicativos se pueden observar dos periodos de extensión cronológica muy desigual. El primero, que cubriría desde la Edad Antigua hasta la primera mitad del siglo XX y el segundo, que, desde entonces, llegaría hasta nuestros días. Situar el turning point de este relato en un momento tan cercano a nosotros no es ni un capricho de contemporaneísta ni pecar de presentismo. Autores como Robert C. Solomon o Barbara Rosenwein han demostrado la existencia de una línea de continuidad que vinculó las reflexiones sobre los sentimientos elaboradas desde los clásicos griegos, pasando por la Edad Media y Moderna hasta bien entrado el siglo pasado. Este lugar común fue la interpretación de la emocionalidad como un fenómeno interno del cuerpo humano, que abarcaba una relación de sentimientos universales a todos los individuos y que respondía a una lógica ajena al raciocinio o a la conciencia. Los afectos, así vistos, funcionaban dentro del cuerpo humano como una suerte de fuerzas que pugnaban por liberarse y manifestarse al exterior. El modelo «hidráulico», denominado así por la frecuencia con que estos afectos eran asemejados a líquidos burbujeantes

4 Jan Plamper, The History of Emotions (Oxford: Oxford University Press, 2005), 9-10. 
que amenazaban con desbordar a los individuos, remitía de forma directa a la teoría de los humores, tan extendida en los siglos medievales, y que había sido transmitida en sus presupuestos básicos (los arriba enunciados) a los teóricos modernos y contemporáneos, hasta llegar a impregnar las propias teorías freudianas sobre las dinámicas subconscientes que fluyen a través del sistema nervioso y se manifiestan en comportamientos inesperados ${ }^{5}$.

La validez de este modelo hidráulico comenzó a declinar en los años sesenta del siglo XX, coincidiendo con el auge de la psicología cognitiva y su interés por las emociones ${ }^{6}$. Los experimentos efectuados durante esta década descartaron la interpretación de los afectos como fuerzas internas e intentaron probar que estos eran el resultado de la percepción de un objeto o situación y de su posterior procesamiento cerebral. Desde esta perspectiva, las emociones aparecían como reacciones racionales que dependían de la predisposición de cada individuo ante una situación dada. Reconociendo que existían unas emociones básicas compartidas por todos los individuos (el miedo sería el mejor ejemplo), se admitía también que estas surgían en diferentes circunstancias en función de los juicios de valor o las preconcepciones de cada persona $^{7}$. Así, con la introducción por parte de Magda B. Arnold de la dimensión "valorativa» en este modelo, (esto es, la propuesta de que entre el estímulo físico y la respuesta se producía una evaluación acerca de lo que está aconteciendo; la secuencia sería: percepción-valoración-emoción), la psicología

5 «The hydraulic model has certainly been the dominant if not definitive structural theory of the psycology of emotions [...] the same model has been almost exclusive in our prescientific thinking for over two thousand years", en Robert C. Solomon, The Passions: Emotions and the Meaning of Life (Indianapolis: Hackett, 1993), 85; Barbara Rosenwein, "Worrying about emotions in History," American Historical Review Vol. 107, $\mathrm{n}^{\circ} 3$ (june 2002): 834-836.

6 Aunque es cierto que esta teoría humoral o hidráulica sigue ampliamente presente en lo que se podría considerar el lenguaje popular de las emociones. Así lo demuestran, para el caso de los idioms anglosajones, estudios como el de George Lakoff, Women, Fire, and Dangerous Things: What Categories Reveal about the Mind (Chicago: University of Chicago Press, 1987), («La conceptualización del miedo», 380 y ss.).

7 Stanley Schachter y Jerome E. Singer, «Cognitive, Social and Phycological Determinants of Emotional State,» Psychological Review Vol. 69, n 5 (1962): 379399, DOI: https://doi.org/10.1037/h0046234. 
cognitiva abrió las puertas a la consideración del papel que la cultura y la historia tenían en la generación de sentimientos e hizo posible un diálogo con las ciencias humanas que, como se verá más abajo, continúa en la actualidad ${ }^{8}$.

Junto a la psicología, la antropología constituyó el otro espacio principal para la renovación de los paradigmas explicativos sobre las emociones. Los estudios antropológicos desarrollados en la primera mitad de siglo habían dado los primeros pasos en la desestabilización de la idea de emociones panculturales, ensanchando así la visión de las posibilidades afectivas de los sujetos al mostrar las diferentes formas en que los sentimientos eran vividos y expresados a lo largo y ancho del planeta. No obstante, la premisa de que existía un elemento emocional común a todos los individuos se mantuvo como una concepción implícita en la mayoría de trabajos de la disciplina hasta la década de 1980, cuando la adhesión generalizada de la antropología al construccionismo social permitió sostener la tesis de que los sentimientos se conforman y perfilan culturalmente sin que exista algo parecido a un repertorio básico o universalmente compartido. Para los defensores del construccionismo social, las emociones se generan y se organizan de modo diferente según cada cultura, en función del lenguaje, las prácticas, las expectativas y los valores que esta promueva ${ }^{9}$.

Desde este enfoque, los estudios psicológicos cognitivos que habían tratado de demostrar el papel de lo contingente en la emergencia de emociones esenciales adolecían de un "reduccionismo biologicista» o "empirismo simplista», en palabras de Rom Harré ${ }^{10}$, que les impedía comprender la contingencia y la variedad de formas de sentir que se manifiestan desde las culturas minoritarias y locales hasta las mayoritarias. Un debate entre posturas cognitivistas

\footnotetext{
8 Magda B. Arnold, Emoción y personalidad (Buenos Aires: Losada, 1970).

9 Catherine A. Lutz, Unnatural Emotions: Everyday Sentiments on a Micronesian Atoll and Their Challenge to Western Theory (Chicago: University of Chicago Press, 1985), 3-13.

10 Rom Harré, ed., The Social Construction of Emotions (Oxford: Basil Blackwell, 1986), 4.
} 
y constructivistas que se complicó aún más con la popularización en estos años de las teorías del psicólogo Paul Ekman, que contradecían diametralmente las posturas del construccionismo social y defendía a partir de estudios de expresión facial en diferentes culturas la existencia de un conjunto de emociones básicas (recopiladas por Akman en una lista que, paradójicamente, fue variando con el tiempo) ${ }^{11}$.

En cualquier caso, hacia final de siglo se fue dibujando un consenso tácito entre los investigadores en ciencias sociales y humanas acerca de la idea de que, si bien la naturaleza humana nos predispone hacia un cierto tipo de respuesta emocional, la cultura tiene un papel determinante como moldeadora de estas propensiones ${ }^{12}$. La cuestión más controvertida radicaba en averiguar en qué consistía esa predisposición biológica a sentir de un modo u otro y de qué modo esta inclinación innata podía conciliarse con la fuerza moldeadora de la cultura. Una pregunta que allanó el camino a la incursión de la neurociencia, disciplina que desde hace aproximadamente dos décadas ha logrado situar sus explicaciones sobre el cerebro y el cuerpo en el centro de la discusión sobre las emociones.

Josheph LeDoux y Antonio R. Damasio han sido los dos nombres más citados por la historiografía cuando de buscar un apoyo en la neurociencia se trata. Los estudios sobre la función cerebral de LeDoux sostuvieron la existencia de dos vías cerebrales paralelas por medio de las que la información sensorial es transformada en emoción: una, la del córtex, que permite cierto cálculo y reflexión sobre lo que acontece (apartarse de un animal peligroso, por ejemplo), y otra, a través de la amígdala, todavía más veloz, que genera una respuesta corporal casi instantánea (pulso acelerado) y pre-

11 Paul Ekman y Wallace V. Friesen, «Facial Sign of Emotional Experience,» Journal of Personality and Social Psychology Vol. 39, $\mathrm{n}^{\circ} 1125$ (1980): 1125-1134. La amplia recepción de las teorías de Akman se puede observar, todavía hoy, en el éxito de series de televisión como «Lie to me» (en español «Miénteme»), en la que un equipo de investigadores ayuda al FBI a detectar las mentiras de los sospechosos basándose en sus gestos faciales.

12 William Reddy, «Historical Research on the Self and Emotions,» Emotion Review Vol. $1, n^{\circ} 4$ (2009): 306. 
racional ante el estímulo ${ }^{13}$. Fruto de estas investigaciones, la amígdala se convirtió en el centro de los estudios antropológicos e historiográficos sobre los sentimientos considerados «negativos», y en particular del miedo, emoción sobre la cual había desarrollado LeDoux la mayoría de sus experimentos ${ }^{14}$.

Su premisa de que las emociones son indispensables para dar una respuesta correcta a los estímulos que recibe nuestro cuerpo han estado igualmente presentes en las investigaciones del también neurocientífico Antonio $R$. Damasio. Dos ideas vertebran su propuesta, de gran calado en los estudios humanísticos: la fabricación de las emociones se produce en el córtex pre-frontal del cerebro, desde donde se generan continuas respuestas emocionales que nos ayudan a predecir el futuro, a planificar nuestras decisiones de forma ventajosa de acuerdo a las normas sociales y a relacionarnos con el mundo. Las investigaciones con pacientes que sufrían un daño en estas secciones del cerebro encargadas para Damasio- de generar emociones, demostró que aun conservando el resto de capacidades mentales intactas (habla, memoria, cálculo...) un individuo con esta zona del cerebro afectada, y en consecuencia inhábil para emocionarse, veía seriamente afectada su capacidad de supervivencia. Por otro lado, lo que acontecía en estas zonas del cerebro iba más allá de ser una mera actividad mental e implicaba directamente al cuerpo en su completa fisiología. Las respuestas emocionales se producen gracias a la capacidad de nuestro cerebro para cartografiar lo que acontece en nuestro cuerpo, que utilizamos como referencia de base para las explicaciones que nos damos del mundo: «nuestros pensamientos más refinados y nuestras mejores acciones, nuestras mayores alegrías y nuestras más profundas penas utilizan el cuerpo como vara de medir", aseguraba Damasio ${ }^{15}$.

13 Joseph LeDoux, The Emotional Brain: The Mysterious Underpinning of Emotional Life (New York: Simon and Schuter, 1996),163-168.

14 Un buen ejemplo del impacto de las teorías sobre la amígdala como epicentro cerebral de las emociones en Jan Plamper y Benjamin Lazier, eds., Fear across the disciplines (Pittsburgh: University of Pittsburgh Press, 2012), especialmente el capítulo de Arne Öhman, "The Biology of Fear: Evolutionary, Neural, and Psychological Perspectives,» 35-50.

15 Antonio R. Damasio, Descartes' Error. Emotion, Reason and the Human Brain (Nueva York: Putman, 1994), 16. 


\section{Gira la historia y llegan las emociones}

La constante sucesión de lecturas sobre la naturaleza de nuestra sentimentalidad no explica por sí misma el interés masivo que, desde finales del pasado siglo hasta hoy, han adquirido los afectos en el campo de las ciencias humanas. Para comprender la atención creciente que los historiadores prestan al pasado de nuestros sentimientos es necesario poner en paralelo la revisión esbozada en las páginas anteriores con la consideración, que este punto se propone, de la progresiva seducción por lo emocional que la historiografía ha ido mostrando y que ha desembocado en el llamado "giro afectivo" o «affective turn» a principios del siglo XXI.

En 1941, décadas antes de que las emociones tuviesen un lugar preeminente en las investigaciones sobre el pasado, Lucien Febvre advertía que, aunque los sentimientos siempre hubieran estado presentes en los relatos de los historiadores (en las descripciones, por ejemplo, de aquellas grandes personalidades que todavía a principios del siglo XX eran el fundamento de las explicaciones historiográficas), estos nunca habían sido merecedores de una atención específica, lo que ocasionaba a menudo un incómodo presentismo fruto de la atribución de sentimientos actuales a personajes cuyo universo afectivo no era ni lejanamente conocido ${ }^{16}$. Con ello, su trabajo «La sensibilité et l'histoire» devino en símbolo de una llamada al estudio de lo que a principios de los años cuarenta era todavía considerado como una oscura dimensión de la condición humana.

Lo cierto es que, aunque Febvre podría haber sido el primero en lanzar explícitamente el órdago a los historiadores, su atención a los sentimientos no era, a principios de los años cuarenta, del todo inédita. Dos hitos en el campo de los estudios medievalistas, El otoño de la Edad Media de Johan Huizinga y El Proceso de Civilización de Norbert Elias, escritos a principios de siglo (aunque traducidos al inglés en 1924 y en 1969, lo que

16 Lucien Febvre, «La sensibilité et l'histoire: Comment reconstituer la vie affective d'autrefois ?,» Annales d'histoire sociale, ${ }^{\circ} 3$ (1941): 5-20. 
explica la tardía recepción del último) habían cimentado una lectura del pasado en la que el control de las emociones jugaba un papel primordial en la explicación del cambio histórico ${ }^{17}$. Deudores de la interpretación hidráulica de $\operatorname{los}_{\text {afectos }}{ }^{18}$, ambos relatos compartían una visión de la Edad Media como un periodo dominado por una emocionalidad desbordada, que solo había empezado a avanzar hacia la meta civilizatoria cuando la vergüenza y el autocontrol emergieron en el seno de la cultura cortesana medieval e irradiaron progresivamente al resto de la sociedad ${ }^{19}$. Estas tesis de Huizinga y Elías sobre los cambios emocionales fueron compartidas por otros historiadores de la primera mitad de siglo, muy especialmente aquellos dedicados al estudio de la Edad Media -incluido el propio Febvre-, aunque permanecieron como un testimonio solitario de un interés por las emociones todavía ciertamente escaso $^{20}$.

Hubo que esperar que la cultura -el sentido culturalistaentrara a remover los cimientos de la disciplina historiográfica en lo que algunos denominaron "cultural turn» o "giro cultural» para poder ver cómo las emociones volvían a escena, aunque desempeñando un papel diferente al que habían ocupado en los estudios de la primera mitad de siglo. Es bien sabido que la historia social, en pleno auge a principios de los años sesenta,

17 Johan Huizinga, El otoño de la Edad Media: estudios sobre las formas de la vida y del espíritu durante los siglos XIV y XV en Francia y en los Países Bajos (Madrid: Revista de Occidente, 1945); Norbert Elias, El proceso de la civilización: investigaciones sociogenéticas y psicogenéticas (Madrid: Fondo de Cultura Económica, 1987).

18 Rosenwein, «Worrying about Emotions,» 834.

19 La obra de Elias ha sido criticada por esta visión lineal o progresiva de los procesos históricos y a la vez reivindicada como un trabajo visionario en su concepción de cómo el entorno puede afectar y moldear las propensiones emocionales de los individuos. Véanse Robert van Krieken, «Norbert Elias and Emotions in History,» en Passion, Power and Elias: Emotional Styles and Historical Change, eds. David Lemmings y Ann Brooks (London: Routledge, 2014); Mónica Bolufer, coord., Del uso de las pasiones: la civilización y sus sombras. Historia Social, 81 (Valencia: Fundación Instituto de Historia Social, 2015), 68.

20 Por ejemplo, la obra coetánea de C. S. Lewis, La alegoría del amor: estudio de la tradición medieval (Buenos Aires: Eudeba, 1969) donde su autor expone la evolución del amor adúltero medieval hacia el amor romántico moderno. La inclusión de Febvre y de su obra Amour sacre, amour profane en esta nómina de autores influenciado por el relato sobre el progresivo refinamiento de las pasiones en Reddy, «Historical Research on the Self and Emotions,» 33. 
comenzó a ser cuestionada en sus presupuestos básicos desde muy pronto por quienes creían necesario priorizar el estudio de la dimensión cultural o simbólica de los fenómenos históricos, buscando estructuras objetivas que explicaran causalmente la acción de los individuos. El resultado fue la historia cultural (o sociocultural) que, profundamente influida por la historia de las mentalidades francesa, y tomando prestado métodos, categorías, temas y fuentes de una antropología también en renovación por estos años, comenzó a diversificar los intereses y a sacar a la palestra nuevos objetos de investigación, como las lágrimas, la violencia o el matrimonio ${ }^{21}$. Nuevos objetos (y nuevas preguntas) que, si no eran explícitamente las emociones, sí manifestaban ya una clara disposición a tenerlas en cuenta en su historicidad.

La fertilidad de la nueva historia cultural y su diversidad de propuestas teóricas colaboró en el auge de nuevas vías de estudio como la historia de las mujeres, que contribuyó notablemente a poner los sentimientos en primer plano e hizo posible la introducción en la historiografía de una categoría de análisis, el género, cuyo diálogo con la historia de las emociones sigue demostrándose a día de hoy más que productivo. Así, desde principios de los años setenta, y animadas tanto por la renovación de la disciplina como por los efectos todavía cercanos de la segunda ola feminista en Estados Unidos, autoras como Natalie Zemon Davis enfocaron sus trabajos sobre la sexualidad del pasado desde una perspectiva antropológica, lo que supuso un avance determinante en la tarea de desnaturalizar las visiones esencialistas respecto al cuerpo y sus representaciones ${ }^{22}$. Igualmente, las investigaciones sobre la construcción histórica de las desigualdades entre mujeres y hombres emprendidas por historiadoras como Joan Scott

\footnotetext{
21 Natalie Zemon Davis, «Los ritos de la violencia,» en Natalie Z. Davis, Sociedad y Cultura en la Francia moderna (Barcelona: Crítica, 1993), 149-185; Anne VincentBuffault, Histoire des larmes: XVIIIe-XIXe siècles (Marseille: Rivages, 1986); Lawrence Stone, Familia, sexo y matrimonio en Inglaterra, 1500-1800 (México: Fondo de Cultura Económica, 1990).

22 Natalie Zemon Davis, «Un mundo al revés: las mujeres en el poder,» en Historia y género. Las mujeres en la Europa moderna y contemporánea, ed. Mary Nash y James S. Amelang (Valencia: Institució Alfons el Magnánim, 1990), 59-92. [edición original 1975].
} 
subrayaron la importancia que la atribución de una naturaleza sentimental diferenciada a ambos sexos había tenido en este proceso. Al mismo tiempo, autores que luego tendrían un papel nuclear en el desarrollo de la historia de las emociones, como Peter N. Stearns, reconocieron la necesidad de iluminar la enorme carga de construcción emocional, que se esconde tras los procesos de creación de las identidades de género, en su caso, la masculina ${ }^{23}$.

De forma paralela al éxito de la nueva historia cultural y sus ramificaciones, otras líneas de investigación fueron introduciendo en los estudios históricos nuevas variables para explicar el comportamiento humano que se distanciaba de la óptica materialista. La psicohistoria, ejemplo de la efervescencia creativa de la disciplina en estos años, intentó sacar a la luz los motivos inconscientes que determinan la acción individual en el pasado aplicando los modelos explicativos contemporáneos de la psicología. Un modo de proceder que reportó no pocas críticas a los psicohistoriadores por el anacronismo de las categorías que empleaban, y por el presentismo que destilaban sus interpretaciones sobre la vida emocional (los traumas) de los sujetos del pasado ${ }^{24}$.

Mucha más transcendencia conocerá la primera apuesta en firme por delimitar un campo de investigación específico para las emociones en el marco de la historiografía: la emotionology o emocionología. Teniendo en cuenta lo arriba señalado, no deja de resultar significativo que la definición de este nuevo campo de estudio se hiciera como una reacción a la historia social y que su creación corriese a cargo de dos historiadores, Peter N. Stearns y Carol Z. Stearns - esta última, además, psiquiatra - reconocedores de la importante apuesta de la psicohistoria pero conscientes de sus limitaciones en la

23 Peter N. Stearns, Be a Man! Males in Modern Society (New York: Holmes \& Meier, 1979). La alusión a la convergencia de ambas líneas de investigación (género y emociones) en su trabajo en Jan Plamper, «The History of Emotions: An Interview with William Reddy, Barbara Rosenwein and Peter Stearns,» History and Theory, $\mathrm{n}^{\circ}$ 49 (2010): 237-265, 261.

24 Thomas A. Kohut, «Psychohistory as History,» The American Historical Review Vol. 91, nº 2 (1986): 336- 354, DOI: https://doi.org/10.1086/ahr/91.2.336. 
observación de los contextos históricos ${ }^{25}$. El propósito de los Stearns, tal y como lo enunciaron en su artículo programático de $1985^{26}$, era diferenciar entre la experiencia individual de las emociones y las normas sociales que posibilitan esta experiencia, convirtiendo este segundo aspecto en su objeto de estudio. La emocionología aspiraba a esclarecer cuáles habían sido y cómo se habían modificado los estándares emocionales de las sociedades pasadas, las reglas que han regulado la vivencia y la expresión de los sentimientos, poniendo especial interés en el papel que las instituciones (entendidas en sentido amplio: colegios, ejércitos, familia...) habían tenido en ello. La propuesta de los Stearns sentaba un precedente y al tiempo planteaba un interrogante de largo recorrido: por un lado, en su emocionología estaba el germen de lo que hoy consideramos la historia de la emociones, entendiendo por ello tanto un campo de estudio específico como un repertorio de métodos y categorías analíticas con las que introducir el estudio de los afectos en investigaciones sociales, políticas y culturales de amplio calado. Por otra parte, los Stearns también introducían en la agenda historiográfica una cuestión que puede formularse como pregunta: si los estándares sentimentales y la vida afectiva deben estudiarse de forma diferenciada, ¿cómo suturar después la distancia entre uno y otro?, ¿cómo observar la eventual huella que estos cánones emocionales dejan en la experiencia de los individuos? Volveremos sobre ambos puntos más abajo.

La llamada de Febvre, el ejemplo de Huizinga y Elias, la frescura de la nueva historia cultural, de las mujeres y de género, junto con la apuesta de los Stearns por la emocionología, fueron allanando el terreno para la eclosión, a finales de los años noventa y a comienzos del siglo XXI, del giro afectivo. No obstante, estos precedentes probablemente hubieran tardado algún tiempo más en dar sus frutos maduros si dos circunstancias no hubieran concurrido para acelerar el proceso de acercamiento de los historiadores al estudio

25 Plamper, «The History of Emotions,» 262.

26 Peter N. Stearn y Carol Z. Stearns, «Emotionology: Clarifing the History of Emotions and Emotional Standards,» American Historical Review Vol. 90, n 4 (1985): 813-36, DOI: https://doi.org/10.1086/ahr/90.4.813. 
de las emociones. La primera de estas circunstancias tiene que ver con la influencia del giro lingüístico en la disciplina historiográfica y con la irrupción de un nuevo paradigma, que hacía del discurso condición de posibilidad para la construcción significativa/cognitiva de la realidad, y que consecuentemente emplazaba a los historiadores a tomar el lenguaje como la única vía de entrada posible hacia la comprensión de las relaciones sociales del pasado.

A pesar de su éxito inicial y todavía evidente a día de hoy, desde mediados de los años noventa comenzó a asomar un descontento creciente con algunas implicaciones del giro posmoderno. Victoria E. Bonnell y Lynn Hunt lo diagnosticaron a finales de la década al reunir en un volumen colectivo un grupo de trabajos que intentaban distanciarse de lo que calificaban «formas radicales de culturalismo o posestructuralismo» y aproximarse a otras maneras de entender el cuerpo y el yo que no los redujesen a materia lingüística ${ }^{27}$. También participaron de esta postura crítica filósofos como Brian Massumi, que con su influyente apuesta por la «autonomía del afecto» buscaba escapar al confinamiento discursivo introduciendo la dimensión afectiva como un nuevo plano del ser más allá de la conciencia ${ }^{28}$. En esta misma línea de tránsito del texto al afecto, William Reddy expresó en un artículo elocuentemente titulado "Against Constructionism» $\mathrm{su}$ disconformidad con las versiones más radicales del construccionismo social, que no permitían concebir la existencia de una condición del ser previa al lenguaje y que reducían al sujeto a una entidad «entirely empty and wholly plastic» ${ }^{29}$. Su propósito era rescatar a las ciencias sociales

27 Victoria E. Bonnell y Lynn Hunt, eds., Beyond the Cultural Turn. New Directions in the Study of Society and Culture (Berkley-Los Ángeles: University of California Press, 1999), 11 y 21.

28 Massumi es uno de los autores que distinguen entre afecto y emoción. Por afecto entiende una «intensidad» indeterminada previa a la conciencia; por emoción, la actualización de dicho afecto, su identificación, extrapolada a los terrenos de la conciencia. Afecto y emoción «siguen diferentes lógicas y pertenecen a diferentes órdenes», Brian Massumi, «The Autonomy of Affect,» Cultural Critique, $\mathrm{n}^{\circ} 31$ (The Politics of Systems and Environments, Part II) (1995): 83-109, 88.

29 William Reddy, "Against Constructionism: The Historical Ethnography of Emotions,» Current Anthropology Vol. 38, ${ }^{\circ} 3$ (1977). Su crítica al construccionismo social enlazaba con otras contemporáneas como las de Ian Hacking, The Social 
del relativismo al que estas concepciones la habían atado, ofreciendo una teoría con la qué observar el efecto del lenguaje emocional en la experiencia individual de los sujetos (un lapso pendiente de cubrir también en la propuesta de los Stearns) y que permitiese a los historiadores emitir juicios políticos en función del bienestar o malestar que cada vivencia reportar a tales sujetos. El resultado fue su teoría sobre los «emotives», a la que aludiremos en el siguiente punto. Baste ahora subrayar que el trabajo de Reddy constituyó el mejor ejemplo de cómo esta insatisfacción compartida por historiadores y otros científicos sociales respecto a las explicaciones puramente lingüísticas era un punto de partida para la reflexión sobre el papel de las emociones, en la comprensión de la experiencia de los sujetos del pasado ${ }^{30}$. Como ha señalado más recientemente Javier Díaz Freire, mitigar la deriva idealista del postestructuralismo no equivalía a reciclar una epistemología de las esencias o de términos absolutos. Todo lo contrario: suponía -supone- expandir la visión sobre los modos de construcción del yo para integrar las emociones y su vivencia corporal entre los factores que explican este proceso dinámico ${ }^{31}$. En este deseo de replantear el giro lingüístico conservando sus logros y enmendando sus posibles carencias estuvo, por tanto, el principal factor desencadenante del «giro afectivo» en la historiografía.

No son pocos los autores que, reconociendo la voluntad de un cambio epistemológico como el factor desencadenante del giro afectivo, coinciden en acentuar el papel que el contexto cultural y social más amplio tuvo en esta transformación. Plamper, por ejemplo, ha localizado en los atentados del 11 de septiembre de 2001 el comienzo de un proceso de invasión de las explicaciones emocionales para los problemas de la vida

Construction of What? (Boston: Harvard University Press, 1999); o Cas Wouters, «Reseña de The Social Construction of Emotions, editado por Rom Harré,» Theory, Culture \& Society Vol. 6, nº 4 (1990): 327-351.

30 Clare Hemmings, «Invoking Affect: Cultural Theory and the Ontological turn,» Cultural Studies, nº 19 (2005): 548-567.

31 José Javier Díaz Freire, «Cuerpo a cuerpo con el giro lingüístico,» Arenal. Revista de historia de las mujeres Vol. 14, $\mathrm{n}^{\circ} 1$ (Miren Llona y Nerea Aresti, "Cuerpos, discursos e identidades») (2007):5-29. 
contemporánea ${ }^{32}$. Este nacimiento de una supuesta "sociedad emocional» ("affective society») propia de nuestro tiempo habría sido, para autores como Monica Greco y Paul Stenner, la causa de que las ciencias sociales hayan incorporado a su agenda el estudio de los sentimientos ${ }^{33}$. En este punto $-\mathrm{y}$ sin dejar de resultar paradójico- la relación entre contexto (sociedad afectiva) e individuos (historiadores de las emociones) no está del todo clara. En vista de lo señalado más arriba, esta última interpretación de las ciencias sociales -en este caso de la historiografía - como una simple caja de resonancia de las inquietudes ambientales no es del todo sostenible. Tampoco lo es la que imagina a la disciplina funcionando según una lógica autónoma e independiente del mundo en el que se desarrolla.

Un posible punto de encuentro entre ambos extremos puede pasar por considerar que el desenvolvimiento trepidante de la historiografía en los últimos años no solo ha situado a la disciplina ante nuevos retos intelectuales, también ha provocado nuevas relaciones emocionales de los historiadores con su trabajo ${ }^{34}$. En la bisagra entre los dos últimos siglos, la relación de buena parte de los historiadores con su práctica profesional se vio cruzada por un sentimiento de incertidumbre claramente compartido con otras disciplinas. La cuasi desmaterialización lingüística de la disciplina provocó un estado de preocupación del que los innumerables trabajos sobre los excesos de los giros son buena prueba. Esta reacción emocional respecto a la praxis vino acompañada, por supuesto, de debates mucho más específicos sobre los caminos

32 Plamper, The History of Emotions, 60-62.

33 «The turn to affect and emotions in social science reflects and responds to this broader social development,» eds. Monica Greco y Paul Stenner, Emotions. A social science Reader (Nueva York: Routledge, 2008), 11.

34 Un buen ejemplo del modo en que la relación emocional del historiador con el devenir de su disciplina condiciona su trabajo es Una línea torcida, la autobiografía intelectual de Geoff Eley en la que el historiador explica singularmente las convulsas últimas décadas de su profesión y lo hace organizando emocionalmente los tiempos historiográficos, articulándonos en función de las que cree que han sido las «sensibilidades» mayoritarias en cada momento: mientras los capítulos «Optimismo» y «Desilusión» se refieren a las formas de hacer historia social en auge entre los años sesenta y ochenta, «Reflexión» alude a la llegada del giro cultural desde EEUU y «Desafío» a la cambiante situación de la historiografía en 2005. Geoff Eley, Una línea torcida De la historia cultural a la historia de la sociedad (Valencia: PUV, 2008). 
de salida posibles; algunos hemos citado más arriba. Pero lo que interesa aquí es señalar que este estado de expectación, y en algún caso ansiedad, desembocó en un interés por las emociones gracias a las investigaciones que otras disciplinas vecinas estaban perfeccionando simultáneamente. Estas fórmulas no solo animaron a la historiografía a releer la historia de las emociones producidas antes de la historia de las emociones, sino que también le prestaron enfoques y categorías de análisis, además de ayudar a hacer inteligible aquella incertidumbre y a proyectarla en forma de debate intelectual. El nacimiento en 2008 de instituciones como el Center for the History of Emotions, del Instituto Max Planck, y el Centre for the History of Emotions, de la Universidad Queen Mary, no puede desvincularse de tales inquietudes ${ }^{35}$. Por su parte, la "sociedad emocionada" -el boom de las emociones por doquier en Occidente- contribuyó y contribuye a agitar más este debate historiográfico e interdisciplinar; pero no es su causa, sino uno de los factores que explican su vitalidad, su acervo infinito de temas y, seguramente, las urgencias por calificar estos cambios como un (nuevo y revolucionario) giro en la disciplina.

Más allá de eso, ¿qué implica para la propia historiografía hablar de "giro afectivo»? En 2012, la $A H R$ reunió a un grupo de historiadores para reflexionar sobre los "giros historiográficos» de las últimas décadas. Aunque el conjunto guardaba un cierto equilibrio entre defensores y detractores del término, las observaciones de estos últimos destacaban por su valor como advertencia para futuros entusiastas de los giros por llegar. Bautizar a un momento historiográfico de "giro» -recordabanno es una decisión inocua ni un modo de encontrar un sinónimo rápido a "historia»: "giro cultural» no es igual a "historia cultural». Además, señalaban que el uso común de este término en la historiografía lo había acabado convirtiendo en una forma consensuada de aludir a una transformación significativa en las categorías, los métodos y los objetos de estudio de la disciplina que rompe, o al menos cuestiona fuertemente, los cimientos

35 Ute Frevert, «The Modern History of Emotions: a Research Center in Berlin,» Cuadernos de Historia Contemporánea, Vol. 36, (2014): 31-55. 
epistemológicos del paradigma (el giro) precedente. Todo ello, además,presuponiendociertahomogeneidad tantoenlapráctica de esta nueva historiografía como en la periodización que se produce, frecuentemente atribuida de forma reduccionista a una generación concreta de historiadores. Así, para sus críticos, los giros historiográficos serían más el resultado de un afán nominalista por bautizar y secuenciar a posteriori los cambios ocurridos en los años ochenta y noventa, que el reflejo de una voluntad de indagar en la multiplicidad de líneas de debates que se abrieron y enfrentaron en estos $a^{n}{ }^{36}{ }^{36}$. Por eso no es de extrañar que, al ser preguntado por el "affective turn", William Reddy respondiese que él prefería hablar de "tendencia» ${ }^{37}$; sin embargo, y dada la popularidad innegable que ha adquirido la fórmula "giro afectivo" en los últimos años, parece que lo más práctico sea precisar preventivamente lo que comprendemos por giro afectivo y reflexionar sobre sus ventajas.

La irrupción de las emociones en las agendas de los historiadores supone un desplazamiento desde las antiguas concepciones, que recluían a los sentimientos a un rincón oscuro y universalmente compartido de la irracionalidad humana, hasta un lugar central en la explicación de la experiencia y el comportamiento de los individuos. Esta visión remozada de las emociones se beneficia de los logros de la historia cultural y postsocial; por tanto, lejos de matar al padre (o a sus hermanos mayores) retoma lo más valioso de unos paradigmas que no cree superados, sino vigentes y en necesario diálogo con la historia de las emociones. Por ello, posee una tendencia manifiesta a hibridarse con categorías de análisis, como el género, y a ponerse a girar con otros giros vecinos: el espacial, el corporal o (¿por qué no?) el medioambiental, o el psicopolítico. Además, este giro emocional sacude y a la vez seduce a la disciplina por la pluralidad e interdisciplinariedad

36 Judith Surkis, «When Was the Linguistic Turn? A Genealogy?,» American Historial Review (Forum: Historiographic "Turns" in Critical Perspective») Vol. 117, $\mathrm{n}^{\circ} 3$ (2012): 700-722; James W. Cook, «The Kids Are All Right: On the "Turning" of Cultural History," American Historical Review (Forum: Historiographic "Turns" in Critical Perspective») Vol. 117, $\mathrm{n}^{\circ} 3$ (2012): 746-771.

37 Plamper, «The History of Emotions: An Interview,» 248. 
de las aportaciones que trae bajo su paraguas. Es un giro, finalmente, cuya periodización importa poco al lado de la antigua genealogía de estudios humanísticos o científicos que está trayendo a primera línea: el giro podrá estar en marcha desde el cambio de siglo, pero la historia de las emociones (en sus variadas acepciones) viene madurando desde mucho más lejos. En definitiva, entendemos este giro afectivo, que ha poblado de emociones nuestras inquietudes historiográficas, como un fenómeno plural en toda su amplitud y como un acontecimiento epistemológico en tránsito y lejos de estar concluido; lo imaginamos, citando a James W. Cook «as turns, not turn; as turning, not turned» ${ }^{38}$.

\section{Una caja de herramientas para el historiador}

Prueba de este carácter dinámico es el dilatado espectro de formulaciones teóricas y apuestas metodológicas para el estudio de los sentimientos, que han sido ofrecidas en las últimas décadas. Vistas en perspectiva, resulta evidente que estas herramientas han ido configurándose en función de las preguntas que la historiografía de las emociones se ha hecho a sí misma. Por eso no es de extrañar que las categorías de análisis de las emociones se hayan pensado como instrumentos útiles para dar respuesta a los dos problemas que vertebran la investigación sobre el pasado de los afectos: la relación entre experiencia emocional y expresión lingüística y la correspondencia entre cambio histórico y transformaciones emocionales. La valoración crítica de la literatura producida desde mediados de los años ochenta hasta el presente da buena cuenta de esta relación entre problemas y herramientas para la investigación.

Cuando Peter y Carol Stearns inauguraron en 1985 los estudios de emocionología como un sub-campo de la historia social, ambos establecieron una base conceptual y un método o research strategy de gran recorrido para la historia de los sentimientos. La primera se fundamenta en la distinción explícita entre los estándares afectivos predominantes en un

38 Cook, «The Kids Are All Right,» 771. 
tiempo/lugar concreto y las emociones, en tanto que reducto de una subjetividad en continua relación con los objetos de su entorno. La emocionología se abstiene de estudiar la relación entre norma y experiencia -esto es, de qué modo estos reglamentos afectivos modelan la vida sentimental del individuo-, puesto que esta dimensión subjetiva es mucho menos accesible, según los Stearns, que el «contexto emocional» en el que se produce; sin embargo, y pese a esta carencia, la emocionología se ha afianzado desde los años ochenta como un enfoque útil, y casi se podría decir necesario, para el estudio de las emociones del pasado ${ }^{39}$. Su método consiste en examinar documentos personales (diarios, autobiografías, epistolarios, etc.) y literaturas de autoayuda, generados en un marco cronológico y en un tiempo determinado, a fin de detectar en su lenguaje los "valores emocionales» de una época; unos valores cuya transformación es, para los Stearns, no tanto el origen sino más bien la consecuencia indirecta de los cambios sociales $^{40}$.

La propuesta teórica de William Reddy completa en cierta forma las carencias conceptuales de la emocionología y a la vez subsume sus logros, ofreciendo una salida al lapso entre la norma y la vivencia emocional. El núcleo de su planteamiento parte, igual que en el caso de los Stearns, de una diferenciación imprescindible entre la emoción, como material cognitivo albergado en el cerebro y habitualmente inconsciente, y el emotive, un concepto acuñado para definir el esfuerzo interpretativo que todos realizamos al tratar de traducir nuestras emociones -material cognitivo- a un lenguaje compartido. Esta expresión, el emotive, tiene una dimensión constatativa, puesto que describe algo que está ocurriendo, y a la vez tiene un carácter performativo, en tanto que la misma declaración de un sentimiento modela (intensifica o reduce) la emoción misma al desencadenar un proceso cerebral de autoexploración. Así, la noción de emotive tiende el primer puente de los que la historia de las emociones

39 Stearn y Stearns, «Emotionology».

40 La emocionología ha sido puesta en práctica por parte de Peter N. Stearns en trabajos como American Cool: Constructing a Twentieth-Century Emotional Style (Nueva York: New York University Press, 1994). 
ha construido para conectar expresión y vivencia sentimental. Una categoría que viene además acompañada, en la propuesta de Reddy, de otros conceptos acuñados con la intención de poder establecer juicios políticos acerca de las experiencias emocionales de los individuos.

Por un lado, «régimen emocional» es el término que alude al conjunto de emotives, rituales y prácticas afectivas prescritas por un régimen político y que son la base necesaria para el funcionamiento y estabilidad del mismo. Junto con el régimen emocional, Reddy también considera la existencia de «estilos emocionales», igualmente regulatorios, pero no necesariamente constreñidos a las fronteras de un régimen político ${ }^{41}$. La «libertad emocional» definiría la posibilidad que los individuos tienen de "navegar» o transitar entre varios estilos afectivos e incluso buscar matizaciones o alternativas dentro del dominante, construyendo de esta forma una subjetividad más autónoma y libre de imposiciones afectivas. En esta búsqueda de libertad, los individuos pueden encontrar eventualmente lo que Reddy denomina «refugios emocionales», una relación, ritual u organización formal o informal que proporciona cierta libertad a los individuos, porque supone la relajación de las exigencias emocionales de un régimen/ sistema emocional. En oposición a la libertad emocional, el «sufrimiento emocional» sería el resultado de la imposición de un estilo sentimental restrictivo, que impide a los individuos que viven bajo su normativa transitar hacia otros o maniobrar entre varias opciones afectivas, por quedar siempre sujetos a un patrón que no les permite el autoconocimiento y que coarta sus opciones de construirse más allá de lo que pudiera

41 De hecho, el concepto de «estilo emocional» es una reformulación de la primera propuesta de «régimen emocional», criticada por su excesiva dependencia de la idea de régimen político y por la deuda que esta conserva, a su vez, con la noción de Estadonación moderno. Reddy ha tratado de aunar en un mismo paradigma ambos conceptos situándolos como fases diferentes de un eventual proceso: "Style" becomes "regime" when the sum of the penalities and exclusions adds up to a coherent structure, and the issue of conformity becomes definig for the individual», Plamper, «The History of Emotions,» 243. 
considerarse -no sin problema-, el «repertorio emocional oficial» ${ }^{42}$.

Para Reddy, el control afectivo es el lugar donde se ejerce el "poder real», porque la emocionalidad aprendida en un régimen/estilo afectivo moldea lo más esencial de la subjetividad de los individuos y, por tanto, señala los límites para su autodefinición y su concepto del mundo. En función de lo estrictos o permisivos que sean estos regímenes/estilos, podremos hablar de «mejores» y "peores», esto es, podremos emitir un juicio moral sobre su funcionamiento. Finalmente, los emotives son la clave del cambio histórico, en tanto que la búsqueda y acuñación de emotives nuevos, nacidas de la insatisfacción o el sufrimiento creado por los disponibles, no solo supone una transformación lingüística o una simple ampliación de vocabulario, sino que modifica también la relación del individuo que los enuncia consigo mismo (con su emocionalidad), y en consecuencia afecta al mundo que le rodea: le abre horizontes nuevos de relaciones sociales, le permite adoptar y reconocer nuevas actitudes ante situaciones similares, etc ${ }^{43}$.

Mientras que la vinculación entre expresión y experiencia ofrecida por Reddy ha calado en la historiografía posterior y sigue siendo una de las explicaciones más efectivas y citadas, su énfasis en la naturaleza lingüística de los emotives y su interpretación de las causas del cambio histórico han sido criticadas y confrontadas desde otros planteamientos teóricos, como el de las "comunidades emocionales» de Barbara Rosenwein. Desde su sensibilidad de medievalista, la autora señala la importancia de ir más allá de los

42 William Reddy, The Navigation of Feeling. A Framework for the History of Emotions (Cambridge: Cambridge University Press, 2008), 63-130.

43 Reddy aplicó esta teoría por primera vez en su estudio sobre la historia de Francia entre 1700 y 1830 . Su tesis es que durante el siglo XVIII y en oposición a los rígidos códigos de la Corte francesa, comenzó a aflorar en refugios emocionales (como las logias masónicas) un nuevo estilo emocional, un "sentimentalismo» más intenso, cálido, honesto y abierto. Estos cambios emocionales moldearon la transición del Antiguo al Nuevo Régimen, en tanto que el periodo revolucionario fue un intento de convertir aquel estilo emocional marginal en el estilo oficial -en régimen. Reddy, The Navigation of Feeling. 
enunciados emocionales y tener en cuenta otras expresiones o performances no-verbales (tono de voz, gestos, muecas, bailes, palidez, sonrojo, desmayos, reverencias...), así como las secuencias en las que se producen estas manifestaciones (no es igual mostrarse enfurecido y después sentirse culpable que mostrarse enfurecido y después sentirse eufórico), pues nos muestran el modo en que los individuos valoran, además de expresar, sus emociones ${ }^{44}$.

Esta asunción está implícita en su definición de «comunidad emocional» en tanto que grupo de individuos (familias, vecindarios, parlamentos, monasterios, gremios, parroquias...) vinculados por un "sistema de sentimientos» mediante el que definen las emociones propias y ajenas, los lazos afectivos que los unen y los modos de expresión sentimental que alientan, deploran, recuperan o arrinconan ${ }^{45}$. Los individuos que participan de ellas pueden estar en contacto directo, cara a cara; pueden, también, constituir una "comunidad discursiva» ${ }^{46}$ en la que interactúan unos con otros desde la lejanía; pueden, incluso, conformar una comunidad de completos desconocidos que comparten unos valores emocionales, como ocurre en la actualidad con el desarrollo de los medios de comunicación ${ }^{47}$. Estas comunidades emocionales habitualmente se combinan unas con otras a diferentes escalas -continúa Rosenwein- por lo que es frecuente que una comunidad predominante albergue a otras más pequeñas y subordinadas, las cuales participan de la mayoría de valores emocionales que sostienen a la comunidad principal, pero

44 Barbara H. Rosenwein, Generations of Feeling: A History of Emotions, 600 - 1700 (Cambridge: University of Cambridge, 2015), 4 y 8.

45 Rosenwein, "Worrying about Emotions,» 842; Emotional Communities in The Early Middle Ages (Ithaca, Nueva York: Cornell University Press, 2006), 2

46 En el sentido de George Yule, The Study of Language (Cambridge: University of Cambridge, 2010), como un grupo de individuos que comparten un set de normas y expectativas en relación al uso del lenguaje. Barbara H. Rosenwein, Generations of Feeling, 3. Anteriormente, la autora había empleado también "comunidades textuales» tomado el concepto de Brian Stock en The Implications of Literacy: Written Language and Models of Interpretation in the Eleventh and Twelfth Centuries (Princeton: Princeton University Press, 1983); Barbara H. Rosenwein, «Problems and Methods in the History of Emotions,» Passions in Context I (1, 2010): 11, http://www. passionsincontext.de, acceso el 11 de noviembre de 2019.

47 Jan Plamper, History of Emotions, 69. 
que se diferencian en otros rasgos emocionales secundarios del resto de comunidades pequeñas a las que acompañan. Este marco interpretativo permite, además, una visión de los cambios emocionales más fluida y dinámica que la de Reddy, puesto que los sitúa como causa y consecuencia de las transformaciones sociales. En un mismo momento histórico conviven numerosas comunidades emocionales: de la capacidad de una (o varias) de ellas para modificar su sistema de sentimientos dependerá su posibilidad para convertirse en predominante o no; a la vez, el auge de esta(s) comunidad(es) supondrá la extensión e incluso imposición de su modelo en las demás comunidades, alterando o marginando a aquellas más débiles y reducidas ${ }^{48}$.

Más allá de estas propuestas teóricas y metodológicas, en las dos últimas décadas ha aparecido un nutrido grupo de investigaciones que comparten con los Stearns, Reddy y Rosenwein su perspectiva diacrónica en el estudio de las emociones, pero que optan por aislar una en concreto o un grupo de ellas para indagar en sus cambios en el tiempo y el espacio. Un ejemplo de ello es el estudio de Joanna Bourke sobre el miedo, que ilustra el modo en que este sentimiento ha ido modificando su relación con los distintos objetos a los que históricamente ha estado vinculado ${ }^{49}$. También es posible

48 AHR Conversation, 1516. Esta dinámica de cambio y continuidad la ejemplifica Rosenwein a partir de un estudio del mosaico emocional de la Edad Media que trata de desmontar la teoría civilizatoria de Elías ofreciendo una panorámica de las diferentes comunidades emocionales del periodo. En Emotional communities in the Early Middle Ages centra su investigación en Francia y expone los diferentes perfiles que adquieren estas comunidades y la variedad de fuentes disponibles para su estudio: es posible analizar la formación de una comunidad emocional en torno al sentimiento que despierta la muerte, empleando para ello los epitafios de las tumbas. También se puede encontrar una comunidad emocional basada en la lectura común de unos textos, como ocurría con Gregorio el Grande y sus seguidores. En Generations of Feeling, empleando el mismo método, Rosenwein extiende su estudio a Francia e Inglaterra y explica cómo las nociones de lo emocional varían no solo cronológicamente, sino también en función de los registros lingüísticos, e incide en el impacto que tienen los encuentros entre diferentes comunidades sobre los sistemas de sentimientos de cada una de ellas.

49 Por ejemplo, el miedo a la muerte, lejos de ser universal, varía profundamente en función del tipo de muerte que cultural y socialmente se ha imaginado: en el primer tercio del siglo XIX, fue más común en Occidente sentir miedo a una muerte repentina; a finales de siglo, se extendió el miedo a un entierro prematuro -a ser dado por muerto erróneamente; en las sociedades actuales, hay un miedo palpable, 
mapear, como ha hecho Ute Frevert, las metamorfosis de diferentes emociones en el tiempo e incluso conjeturar si los cambios en sus denominaciones constituyen una modificación puramente lingüística o, por el contrario, reflejan una transformación de los mismos afectos -de su explicación, interpretación y valoración externa ${ }^{50}$. En esta línea, otra vía de entrada, que cruza estos supuestos de la historia de las emociones con los postulados de la historia de la ciencia, pero que trasciende ambas y se focaliza en la tensión entre lo vivido subjetivamente y lo representado socialmente, es el estudio de la experiencia; esto es, la pregunta sobre los cambios culturales que han sufrido vivencias concretas, como el dolor ${ }^{51}$.

A este conjunto de formulaciones habría que añadir aquellas propuestas que, sin rechazar la validez a las anteriores, añaden nuevas categorías de análisis pensadas para situar el cuerpo en el centro de la investigación. Estas nuevas concepciones no pueden entenderse sin la huella que el pensamiento foucaultiano sobre el cuerpo, en tanto que lugar mediado e histórica y socialmente contingente, ha tenido en la historiografía; ni tampoco pueden explicarse sin atender a la repercusión que la neurociencia, y particularmente las tesis ya señaladas de Antonio Damasio, tienen sobre la conceptualización de las emociones como un fenómeno corporal que nos ayuda a reconocer el mundo y a orientarnos en él ${ }^{52}$. Esto permite replantear la cuestión de la relación

no tanto a la muerte (que a veces se prefiere repentina), como al sufrimiento y a la agonía. Joanna Bourke, Fear. A Cultural History (Londres: Virago, 2005), 4.

50 Frevet cita, entre otros, el caso de la acedia, la melancolía y la depresión. La primera era una emoción propia de la Edad Media, una mezcla entre languidez, desgana e indolencia. Sus síntomas eran la fiebre y los dolores de extremidades y se interpretaba como una posesión demoníaca. La melancolía era una emoción típica de la Edad Moderna, atribuida a un exceso de bilis negra y relacionada con el genio y la creatividad. La depresión, por su parte, es un producto del siglo XX. Sus síntomas son bien conocidos y su explicación normalmente se relaciona con desórdenes neurobiológicos. Aunque puedan establecerse semejanzas entre ellas, Frevert apunta que esta secuencia no es la de un sentimiento enunciado de forma diferente a lo largo del tiempo, sino la de la pérdida y el surgimiento de diferentes emociones en distintos contextos, Ute Frevert, Emotions in History-Lost and found (Budapest: Central European University Press, 2011), 31-38.

51 Javier Moscoso, Historia cultural del dolor (Madrid: Taurus, 2011).

52 Una reflexión reciente sobre la importancia de mantener el vínculo entre neurociencia y estudios culturales en Rob Boddice, «The History of Emotions: Past, 
entre experiencia emocional y expresión lingüística, desde una concepción del cuerpo como el lugar de la emoción (un cuerpo afectado, sentimentalizado), que no requiere del lenguaje para expresar ni conocer la realidad del mundo porque su propia materialidad/corporalidad le permite acceder a él. Con ello, y de forma más o menos explícita en función del autor, se procura resolver la posible insatisfacción que suscita una historia de las emociones, que trataba de huir del encarcelamiento de lo lingüístico pero que acababa convirtiendo el lenguaje en el único medio de articulación social de lo emocional.

Estas premisas encajan con propuestas como la de Sara Ahmed, que ha puesto de relieve la importancia de la percepción corporal en el desencadenamiento de un estado afectivo y ha empleado el término «impresión» para referir la combinación de sensaciones, pensamientos y emociones que se producen simultáneamente ${ }^{53}$. En sintonía con ello, Monique Scheer ha continuado transitando esta senda hacia la vinculación entre cuerpo y emociones desde su noción de "prácticas emocionales». En su opinión, aportaciones como las de Reddy se aproximaron a la teoría de la práctica pero sin alcanzar a divisar la importancia del engarce entre mente, cuerpo y relaciones sociales en la configuración de las emociones. Analizar las prácticas emocionales supone, para Scheer, reconocer que nuestra acción no es un mero reflejo de lo que sentimos, sino lo que sentimos mismamente; significa explorar cómo las emociones se performativizan en función de un hábito aprendido, y cómo esta performativización aquí sigue a Reddy- afecta a la emoción misma: la acentúa, la aplaca, la transforma en otra distinta, etc ${ }^{54}$. En la misma

Present, Future,» Revista de Estudios Sociales Vol. 62, n 10-15 (2017): 10-15.

53 Sara Ahmed, La politica cultural de las emociones (México DF: UNAM, 2015).

54 Scheer distingue cuatro tipos de prácticas emocionales y sus funciones: las que movilizan e intentan promover corporalmente la aparición de una emoción (como el cortejo); las que nombran, tratando de etiquetar mediante la escritura, el habla o el pensamiento una emoción (ante un terapeuta); las que comunican y tienen como objetivo hacer coincidir el contenido de las afirmaciones verbales con el lenguaje corporal y el contexto que los acompañan (como en un discurso político); y las que regulan, equiparables a lo que conocemos como emocionología. Monique Scheer, "Are emotions a kind of practice (and is that what makes them have a history)? A bourdieuian approach to understanding emotion,» History and Theory, $\mathrm{n}^{\circ} 51$ (2012): 193-220. 
voluntad de búsqueda de un enfoque para el cuerpo y las emociones que ilumine los puntos ciegos de la interpretación lingüística, Mercedes Arbaiza ha propuesto una diferenciación analítica entre dos momentos: el de la experiencia emocional pre-discursiva, en el que se conformaría una subjetividad que, gracias a la capacidad del cuerpo para establecer juicios afectivos sobre su entorno, valora el mundo y nos guía en él; y el de la narrativización de esta experiencia, que sería la traducción de la experiencia emocional previa a términos lingüísticos con los que se representa y politiza lo vivido. Resultados de esta interpretación, el discurso es un elemento central en la significación del mundo, pero no es el único medio a través del cual conocemos y construimos la realidad, siquiera el primero, y por tanto no es el factor que explica en exclusiva el comportamiento de los sujetos; el cuerpo afectado sería, en cambio, el lugar donde habremos de comprender tales transformaciones ${ }^{55}$.

Esta atención al aspecto material de los afectos no puede quedar completa sin una alusión a los estudios que ponen de relieve la dimensión espacial de los sentimientos y que, a pesar de contarse entre los menos transitados por los historiados de las emociones, nos brindan sugerentes rutas para el futuro. En este sentido, se pueden distinguir tres líneas de estudio que aquí solo podremos enunciar y describir brevemente. En primer lugar, sería valioso abrir nuestra mirada a las transformaciones emocionales que acontecen a través de los espacios y prestar así atención a la historia de los afectos más allá de Occidente, lo que implica rastrear la formación de circuitos de intercambio y préstamo entre los diferentes estilos y culturas emocionales que han estado en contacto a lo largo de la historia. Como recordaba Eugenia Lean, lo importante aquí sería no volver a antiguos paradigmas comparativos entre civilizaciones e incorporar los avances alcanzados

55 Mercedes Arbaiza, "Sentir el cuerpo": subjetividad y política en la sociedad de masas en España (1890-1936),» Política y Sociedad Vol. 55, n 1 (2018): 71-92; Mercedes Arbaiza, «Dones en Transició: el feminismo como acontecimiento emocional,» en Mujeres, Dones, Mulleres, Emakumeak. Estudios sobre la historia de las mujeres y del género, eds. Teresa $\mathrm{M}^{\mathrm{a}}$ Ortega López y otras (Madrid: Cátedra, 2018), 267-286. 
desde la historia global, transnacional y postcolonial ${ }^{56}$. En segundo lugar, resultaría provechoso dialogar con la geografía emocional y con las geografías del afecto ${ }^{57}$, herederas ambas del giro culturalista y feminista de la geografía humana ${ }^{58}$, y que comparten con la historia de las emociones una preocupación creciente por convertir el cuerpo en instancia de estudio para la comprensión de la relación entre espacio y emociones. Estos nuevos campos de estudio invitan, por un lado, a interpretar el cuerpo como un mapa de articulaciones espacio-afectivas que ayudan a comprender la vivencia de las emociones (reflejada en expresiones como «tener una profunda tristeza», "estar cerca del llanto», etc.); por otro lado, sugieren una "hermenéutica espacio-emocional» con la que comprender el mundo afectivo de un cuerpo situado. En este sentido, se aborda, por ejemplo, la geografía emocional de las relaciones domésticas y/o familiares; las tejidas en comunidades como las artísticas o religiosas; o las establecidas en el seno de grupos definidos por el espacio que comparten: prisiones, asilos ${ }^{59}$. En último lugar, una tercera propuesta, del todo combinable con las dos anteriores, es la de investigar el modo en que los lugares materiales son emocionalmente experimentados y significados ${ }^{60}$. Esto nos permitiría interrogarnos por los sentimientos nacidos en contacto directo con un emplazamiento, pero también por los surgidos a partir de un recuerdo prestado o por los imaginados en la lejanía de este lugar. Así mismo, podríamos cuestionarnos sobre las consecuencias de estos vínculos afectivos, esclareciendo de qué modo las apropiaciones afectivas de un espacio son el desencadenante de una apropiación efectiva del mismo. Finalmente, para la historia de las emociones también

56 AHR Conversation, 1518

57 La distinción en Steve Pile, «Emotions and affect in recent human geography,» Transactions of the Institute of British Geographers, New Series Vol. 35, $\mathrm{n}^{\circ} 1$ (2010): 5-20.

58 Kay Anderson y Susan J. Smith, «Editorial: Emotional geographies,» Transactions of the Institute of British Geographers Vol. 26, $\mathrm{n}^{\circ} 1$ (2001): 7-10, DOI: https://doi. org/10.1111/1475-5661.00002.

59 Las referencias a estas propuestas en Joyce Davidson y Christine Milligan, «Embodying emotion sensing space: introducing emotional geographies,» Social \& Cultural Geography Vol. 5, nº 4 (2004): 523-532.

60 Margrit Pernau, «Space and Emotion: Building to Feel,» History Compass Vol. $12, \mathrm{n}^{\circ} 7$ (2014): 541-549. 
sería provechosa la pregunta de cómo el vínculo significante con el espacio produce una transformación material/corporal del lugar/sujeto, desencadena conflictos con otros individuos que lo sienten de diferente manera y origina identificaciones y encuentros entre comunidades que imaginan emocionalmente un espacio de forma similar.

\section{A modo de cierre: una historia emocional (e) impura}

Poca duda cabe de que la historia de las emociones es hoy un campo lleno de posibilidades para el estudio del pasado y para la renovación teórica de la disciplina en la que se inscribe. Es cierto que tanta fecundidad ha producido no solo diferentes entramados institucionales dedicados a las emociones, sino también diversos marcos teóricos que, aunque se miran entre sí, en ocasiones no terminan de encajar en sus premisas y derivan en formas diferentes de pensar las emociones y su papel en la explicación del pasado. Por ello, es fácil estar de acuerdo en la oportunidad de hacer historia de las emociones, pero a menudo resulta complicado elegir qué variantes transitar para emprender la investigación. Sin ánimo reduccionista, queremos concluir este artículo con una breve reflexión que no debe leerse en calidad de propuesta programática, sino como sugerencia sobre qué conservar y por dónde crecer en el conocimiento del pasado de los afectos.

Como punto de partida, la historia delas emociones debería acudir a la arena historiográfica conservando lo más valioso del posicionamiento culturalista y posmoderno, su escepticismo respecto a las esencias y la atención a la construcción de los significados, recogiendo a la vez las advertencias de la historia poscolonial sobre nuestra tentación de dar por universales categorías de análisis que, como los objetos que estudian, tienen un origen sociocultural o "situado» que limita su aplicación. Estas mimbres epistemológicas colocarán a la historia de las emociones en un suelo compartido con otras categorías de análisis que llevan décadas enriqueciéndose de estas dos mismas fuentes de renovación. Al hablar de categorías de análisis nos referimos específicamente al género y a la raza, que en sus combinaciones diversas ofrecen un 
abordaje multifocal, que solo puede enriquecer el ya de por sí amplio enfoque emocional.

El género, con su capacidad tan reivindicada como esforzada para la investigación sobre los procesos de construcción de la diferencia sexual, constituye por sí solo un ámbito indispensable para el estudio de los procesos de conformación de la experiencia. La raza, entendida como noción y principio clasificatorio cambiante históricamente, que debe ser abordado en tanto que proceso de racialización (o etnicización), ofrece un segundo escenario privilegiado para el estudio de las intersecciones identitarias que las emociones ayudan a explicar. La historia de las emociones puede ampliar todavía más los márgenes de acción de ambos conceptos al extender el campo de las fuentes posibles para su estudio y al complejizar sus preguntas. Es cierto que tal mestizaje puede conducir a una historia de las emociones que pierda su nombre por el camino y se convierta en una aproximación impura en su enfoque teórico, pero es un peaje que merece la pena pagar por la riqueza de preguntas que permite reunir en torno a un objeto de estudio que ilumina desde ángulos nuevos la historia de cualquier sociedad.

Una de las cuestiones más sugerentes a las que puede aplicarse este instrumental teórico combinado es la de la relación entre estereotipos, regulación y vivencia. En lo que respecta al primero de estos elementos, el de los estereotipos o arquetipos socialmente compartidos, un estudio que se valga de una hibridación entre raza y emociones, sin olvidar tampoco el género como eje determinante en las construcciones sociales, podrá adentrarse, por ejemplo, en la intrincada red de imágenes que los grupos mayoritarios han generado, para representar y relegar a la subalternidad a pueblos como el romaní. Una densa red de imágenes en la que la atribución emocional y la construcción racial se refuerzan recíprocamente para dar solidez a una representación del pueblo romaní como la «bárbara» otredad de la "civilizada» sociedad occidental ${ }^{61}$.

61 María Sierra, «Uncivilized Emotions: Romantic Images And Marginalization of The Gitanos / Spanish Gypsies,» Pakistan Journal of Historical Studies Vol. 1, n ${ }^{\circ} 1$ (2016): 43-64. 
Por otro lado, la articulación de género y emociones es también una herramienta útil para examinar de qué manera los cánones sexuales y las normativas emocionales que regulan la expresión sentimental y la identidad de género se apelan y modifican mutuamente. En este sentido, podríamos preguntarnos, en primer lugar, si las emociones consideradas como el afecto-matriz de una comunidad adquieren perfiles normativos diferentes al referirse a los hombres y mujeres que conforman esta comunidad. La alegría como componente nuclear de la cultura del fascismo español sería un claro ejemplo de esto, en tanto que de esta emoción se crearon dos versiones, una masculina y otra femenina, que regían el modo en que esta alegría o entusiasmo falangista debía sentirse y performatizarse en función del género atribuido al individuo ${ }^{62}$. En esta misma línea de indagación acerca de los estándares sentimentales y sexuales, también parece preciso cuestionarse sobre cómo las masculinidades y feminidades normativas prescriben pautas emocionales que a su vez definen los contornos de estos arquetipos sexuales con mayor nitidez, consolidando así el carácter binario de la construcción de género. La virilidad decimonónica, nacida del encuentro entre una masculinidad definida en sus términos de demostración ante los pares de una capacidad de autocontrol, por un lado, y del régimen emocional del romanticismo por otro, serviría para ilustrar este último caso ${ }^{63}$.

De las vías de exploración antes propuestas, la tercera se refería al ámbito de lo vivido, esto es, a la huella que resulta del impacto de los estereotipos y las normativizaciones en las subjetividades. En este punto puede ser de gran utilidad la noción de experiencia de Joan W. Scott, que la imaginó como un ámbito de interpelación inacabable entre los repertorios semánticos (lingüísticos y -nosotras añadimos-

62 Begoña Barrera, La Sección Femenina 1934-1977. Historia de una tutela emocional (Madrid: Alianza, 2019).

63 María Sierra, Género y emociones en el Romanticismo. El teatro de Bretón de los Herreros (Zaragoza: Institución Fernando el Católico, 2013); María Sierra, «Entre emociones y política: la historia cruzada de la virilidad romántica,» Rúbrica contemporánea Vol. 4, $\mathrm{n}^{\circ} 7$ (2015): 11-25. 
corporales) y unos yoes siempre inestables ${ }^{64}$. Su aproximación a la experiencia intensifica el valor de apuestas como las de Reddy, que invitaban a observar de qué forma un individuo se maneja («navega») entre diferentes estilos emocionales, construyendo una subjetividad afectiva que puede escapar a las constricciones de aquellos. De la combinación de ambas propuestas resulta el desafío, nada trivial, de realizar una hermenéutica de la experiencia que pivote entre las dimensiones vividas, representadas y reguladas del género y los afectos. Para afrontar este reto, no han de faltar estrategias de probado éxito, como la historia biográfica, perfecta aliada en el empeño de esclarecer de qué modo los horizontes de expectativas y los lenguajes disponibles derivaron en formas plurales y diversas de existencia.

Hace años que la historia biográfica se ha demostrado como un marco privilegiado para el entrecruzamiento de diferentes enfoques historiográficos, particularmente el del género, la raza y las emociones, que aplicados al estudio de una vida individual o de un grupo de ellas, permite acceder al difícil ámbito de la construcción histórica de experiencia ${ }^{65}$. De la contingencia de la experiencia y de la infinita red de dimensiones subjetivas en la que se despliega, la historia biográfica puede ayudarnos a arrojar luz sobre las interpretaciones individuales que los sujetos hicieron de los repertorios genérico-afectivos de su tiempo y sobre la influencia que esto tuvo en sus autopercepciones y en sus valoraciones del mundo. Así abordado, el estudio de las culturas políticas del liberalismo, por ejemplo, se enriquece de las aproximaciones que profundizan en las subjetivaciones que sus protagonistas realizaron, tanto de los repertorios emocionales como de los modelos de género existentes, y que

64 Joan W. Scott, «The Evidence of Experience,» Journal of Critical Inquiry Vol. 17, $\mathrm{n}^{\circ} 4$ (1991): 773-797.

65 Mónica Bolufer, Isabel Burdiel y María Sierra, «¿Qué biografía para qué historia?,» en ¿̇Y ahora qué? Nuevos usos del género biográfico, eds. Henar Gallego y Mónica Bolufer (Barcelona: Icaria, 2016), 19-35. 
están en la base de su modo de entender y ejercer tanto la política como su profesión ${ }^{66}$.

Al mismo tiempo, la historia biográfica como marco de cruce entre emociones y género nos abre la posibilidad de contemplar la creatividad con la que las vidas individuales transgreden o se acomodan felizmente (ambas cosas pero en diferentes momentos, normalmente) a las construcciones afectivas y de género que las dominan. Este último sería un relato más que posible para la historia de movimientos sociales como el feminismo, cuyo origen en España parece vinculado a la ruptura con un orden emocional respecto al cual las mujeres de los años sesenta del pasado siglo se fueron mostrando cada vez más disidentes ${ }^{67}$.

En definitiva, la historia de las emociones es un campo abierto a la creatividad del historiador para que la emplee en cualquiera de los múltiples registros en los que su alcance explicativo pueda parecerle útil: como una historia de los sentimientos per se, como un relato sobre los afectados, o como una categoría que multiplica su potencial heurístico en diálogo con otras. Especialmente quienes apuestan por este último recorrido acarician la idea de emociones acaban siendo, incluso, una categoría de análisis tan transversal como el género, útil para cualquier campo o tema de investigación historiográfica. En todo caso, sean cuales sean las opciones posibles convencerán a quien las transite de que las emociones son buenas compañeras de viaje cuando de adentrarse en una comprensión compleja de la historia se trata.

\section{Bibliografia}

Ahmed, Sara. La política cultural de las emociones. México, DF: UNAM, 2015.

66 María Sierra, «Política, romanticismo y masculinidad: Tassara (1817-1875),» Historia y Política, no 27 (2012): 203-226; Darina Martykánová y Víctor M. NúñezGarcía, «Ciencia, patria y honor: los médicos e ingenieros y la masculinidad romántica en España (1820s-1850s),» Studia historica, (2020): en prensa.

67 Arbaiza, «Dones en Transició,» 267-286. 
Anderson, Kay, y Susan J. Smith. "Editorial: Emotional geographies.» Transactions of the Institute of British Geographers Vol. 26, $\mathrm{n}^{\mathrm{o}}$ 1 (2001): 7-10.

Arbaiza, Mercedes. "'Sentir el cuerpo": subjetividad y política en la sociedad de masas en España (1890-1936).» Política y Sociedad Vol. 55, n 1 (2018): 71-92.

Arbaiza, Mercedes. «Dones en Transició: el feminismo como acontecimiento emocional.» En Mujeres, Dones, Mulleres, Emakumeak. Estudios sobre la historia de las mujeres y del género, editado por Teresa $\mathrm{M}^{\mathrm{a}}$ Ortega López y otras, 267-286. Madrid: Cátedra, 2018.

Arnold, Magda B. Emoción y personalidad. Buenos Aires: Losada, 1970.

Barrera, Begoña. La Sección Femenina 1934-1977. Historia de una tutela emocional. Madrid: Alianza, 2019.

Boddice, Rob. «The History of Emotions: Past, Present, Future.» Revista de Estudios Sociales Vol. 62, n 10-15 (2017): 10-15.

Bolufer, Mónica, coord. Del uso de las pasiones: la civilización y sus sombras. Historia Social, 81. Valencia: Fundación Instituto de Historia Social, 2015.

Bolufer, Mónica, Isabel Burdiel, y María Sierra. «¿Qué biografía para qué historia?.» En ¿Y ahora qué? Nuevos usos del género biográfico, editado por Henar Gallego y Mónica Bolufer, 1935. Barcelona: Icaria, 2016.

Bonnell Victoria E., y Lynn Hunt, eds. Beyond the Cultural Turn. New Directions in the Study of Society and Culture. BerkleyLos Ángeles: University of California Press, 1999.

Bourke, Joanna. Fear. A Cultural History. Londres: Virago, 2005.

Cook, James W. «The Kids Are All Right: On the “Turning” of Cultural History." American Historial Review (Forum: Historiographic "Turns» in Critical Perspective») Vol. 117, n 3 (2012): 746-771. 
Damasio, Antonio R. Descartes' Error. Emotion, Reason and the Human Brain. Nueva York: Putman, 1994.

Davidson, Joyce y Christine Milligan. «Embodying emotion sensing space: introducing emotional geographies.» Social \& Cultural Geography Vol. 5, nº 4 (2004): 523-532.

Davis, Natalie Zemon. Sociedad y Cultura en la Francia moderna. Barcelona: Crítica, 1973.

Davis, Natalie Zemon. «Un mundo al revés: las mujeres en el poder.» En Historia y género. Las mujeres en la Europa moderna y contemporánea, editado por Mary Nash y James S. Amelang, 59-92. Valencia: Institució Alfons el Magnánim, 1990.

Díaz Freire, José Javier. «Cuerpo a cuerpo con el giro lingüístico,» Arenal. Revista de historia de las mujeres Vol. 14, $\mathrm{n}^{\circ} 1$ (Miren Llona y Nerea Aresti, "Cuerpos, discursos e identidades») (2007): 5-29.

Ekman, Paul, y Wallace V. Friesen. «Facial Sign of Emotional Experience.» Journal of Personality and Social Psychology Vol. 39, n 1125 (1980): 1125-1134.

Eley, Geoff. Una línea torcida de la historia cultural a la historia de la sociedad. Valencia: PUV, 2008.

Elias, Norbert. El proceso de la civilización: investigaciones sociogenéticas y psicogenéticas. Madrid: Fondo de Cultura Económica, 1987.

Febvre, Lucien. «La sensibilité et l'histoire: Comment reconstituer la vie affective d'autrefois ?.» Annales d'histoire sociale, $\mathrm{n}^{\circ} 3$ (1941): 5-20.

Frevert, Ute. Emotions in history - Lost and found. Budapest: Central European University Press, 2011.

. «The Modern History of Emotions: a Research Center in Berlin.» Cuadernos de Historia Contemporánea Vol. 36, (2014): 31-55. 
Greco, Monica, y Paul Stenner, eds. Emotions. A social science Reader. Nueva York: Routledge, 2008.

Hacking, Ian. The Social Construction of What?. Harvard, Harvard University Press, 1999.

Harré, Rom, ed. The Social Construction of Emotions. Oxford: Basil Blackwell, 1986.

Hemmings, Clare. "Invoking Affect: Cultural Theory and the Ontological turn.» Cultural Studies, nº 19 (2005): 548-567.

Huizinga, Johan. El otoño de la Edad Media: estudios sobre las formas de la vida y del espíritu durante los siglos XIV y XV en Francia y en los Países Bajos. Madrid: Revista de Occidente, 1945.

Kohut, Thomas A. "Psychohistory as History.» The American Historical Review Vol. 91, $\mathrm{n}^{\circ} 2$ (1986): 336-354. DOI: https:// doi.org/10.1086/ahr/91.2.336.

Lakoff, George. Women, Fire, and Dangerous Things: What Categories Reveal about the Mind. Chicago: University of Chicago Press, 1987.

LeDoux, Joseph. The Emotional Brain: The Mysterious Underpinning of Emotional Life. New York: Simon and Schuter, 1996.

Lewis, C. S. La alegoría del amor: estudio de la tradición medieval. Buenos Aires: Eudeba, 1969.

Lutz, Catherine A. Unnatural Emotions: Everyday Sentiments on a Micronesian Atoll and Their Challenge to Western Theory. Chicago: University of Chicago Press, 1985.

Martykánová, Darina, y Víctor M. Núñez-García. «Ciencia, patria y honor: los médicos e ingenieros y la masculinidad romántica en España (1820-1850s).» Studia historica, (2020): en prensa.

Massumi, Brian. «The Autonomy of affect.» Cultural Critique, $\mathrm{n}^{\circ} 31$ (The Politics of Systems and Environments, Part II) (1995): 83-109. 
Moscoso, Javier. Historia cultural del dolor. Madrid: Taurus, 2011.

Pernau, Margrit. «Space and Emotion: Building to Feel.» History Compass Vol. 12, $\mathrm{n}^{\mathrm{o}} 7$ (2014): 541-549.

Pile, Steve. "Emotions and affect in recent human geography.» Transactions of the Institute of British Geographers, New Series Vol. 35, $\mathrm{n}^{\mathrm{o}} 1$ (2010): 5-20.

Plamper, Jan. «The History of Emotions: An Interview with William Reddy, Barbara Rosenwein and Peter Stearns.» History and Theory, $\mathrm{n}^{\circ} 49$ (2010): 237-265.

Plamper, Jan. The History of Emotions. Oxford: Oxford University Press, 2105.

Plamper, Jan, y Benjamin Lazier, eds. Fear across the disciplines. Pittsburgh: University of Pittsburgh Press, 2012.

Reddy, William. The Navigation of Feeling. A Framework for the History of Emotions. Cambridge: Cambridge University Press, 2008.

. «Historical Research on the Self and Emotions.» Emotion Review Vol. 1, nº 4 (2009): 302-315.

«Against Constructionism: The Historical Ethnography of Emotions.» Current Anthropology Vol. 38, ${ }^{\circ}$ 3 (1977): 327-351.

Rosenwein, Barbara H. "Worrying about emotions in History.» American Historical Review, Vol. 107, $\mathrm{n}^{\circ} 3$ (june 2002): 834836.

. Emotional Communities in The Early Middle Ages.

Ithaca, Nueva York: Cornell University Press, 2006.

- "Problems and Methods in the History of Emotions.» Passions in Context I $(1,2010): 1-32 . \mathrm{http}: / / \mathrm{www}$. passionsincontext.de, acceso el 11 de noviembre de 2019.

. Generations of Feeling: A History of Emotions, 600-

1700. Cambridge: University of Cambridge, 2015. 
Schachter, Stanley, y Jerome E. Singer, «Cognitive, Social and Phycological Determinants of Emotional State.» Psychological Review Vol. 69, n 5 (1962): 379-399.

Scheer, Monique. "Are emotions a kind of practice (and is that what makes them have a history)? A bourdieuian approach to understanding emotion.» History and Theory, $\mathrm{n}^{\circ} 51$ (2012): 193-220.

Scott, Joan W. «The Evidence of Experience.» Journal of Critical Inquiry Vol. 17, nº 4 (1991):773-797.

Sierra, María. «Política, romanticismo y masculinidad: Tassara (1817-1875).» Historia y Política, no 27 (2012): 203-226.

Género y emociones en el Romanticismo. El teatro de Bretón de los Herreros. Zaragoza: Institución Fernando el Católico, 2013.

. «Entre emociones y política: la historia cruzada de la virilidad romántica.» Rúbrica contemporánea. 2015 Vol. 4, n 7 (2015): 11-25.

. «Uncivilized Emotions: Romantic Images And Marginalization of The Gitanos / Spanish Gypsies.» Pakistan Journal of Historical Studies Vol. 1, no 1 (2016): 43-64.

Solomon, Robert C. The Passions: Emotions and the Meaning of Life. Indianapolis: Hackett, 1993.

Stearns, Peter N. Be a Man! Males in Modern Society. New York: Holmes \& Meier, 1979.

Stearns, Peter N. American Cool: Constructing a Twentieth-Century Emotional Style. Nueva York: New York University Press, 1994.

Stearns, Peter N., y Carol Z. Stearns. «Emotionology: Clarifying the History of Emotions and Emotional Standards." American Historical Review Vol. 90, no 4 (1985): 813-36. DOI: https:// doi.org/10.1086/ahr/90.4.813. 
Stock, Brian. The Implications of Literacy: Written Language and Models of Interpretation in the Eleventh and Twelfth Centuries. Princeton: Princeton University Press, 1983.

Stone, Lawrence. Familia, sexo y matrimonio en Inglaterra, 15001800. México: Fondo de Cultura Económica, 1990.

Surkis, Judith. "When Was the Linguistic Turn? A Genealogy?.» American Historial Review (Forum: Historiographic "Turns» in Critical Perspective) Vol. 117, $\mathrm{n}^{\circ} 3$ (2012):700-722.

Van Krieken, Robert. "Norbert Elias and Emotions in History.» En Passion, Power and Elias: Emotional Styles and Historical Change, editado por David Lemmings y Ann Brooks, 19-42. London: Routledge, 2014.

Vincent-Buffault, Anne. Histoire des larmes: XVIIIe-XIXe siècles. Marseille: Rivages, 1986.

Wouters, Cas. "Reseña de The Social Construction of Emotions, editado por Rom Harré.» Theory, Culture \& Society Vol. 6, n 4 (1990): 704-707.

Yule, George. The Study of Language. Cambridge: Cambridge University Press, 2010.

Zemon Davis, Natalie. "Los ritos de la violencia.» En Sociedad y Cultura en la Francia moderna, Natalie Z. Davis, 149-185, Barcelona: Crítica, 1993.

\section{Citar este artículo}

Barrera, Bergoña, y María Sierra. «Historia de las emociones: que cuentan los afectos del pasado.» Historia Y MEMORIA, $\mathrm{n}^{\circ}$ Especial (2020): 103-142. DOI: https:/doi. org/10.19053/20275137.nespecial.2020.11583. 